\title{
COVID-19: a prison-breaker?
}

\section{Frédéric Dutheil $^{1}$ - Jean-Baptiste Bouillon-Minois ${ }^{2} \cdot$ Maëlys Clinchamps $^{3,4}$ (D)}

Received: 7 May 2020 / Accepted: 3 June 2020 / Published online: 29 June 2020

(C) The Canadian Public Health Association 2020

\section{Dear Editor:}

Increasing numbers of incarcerated populations result in the health of inmates becoming an essential consideration for public health authorities to reduce health disparities (McLeod et al. 2020). The COVID-19 outbreak has progressed rapidly and was declared a pandemic on 12 March 2020. As such, prevention strategies within prisons and other detention centres are critical to avoid or reduce the spread of infection. Historically, correctional environments are epicenters for infectious disease (Turner and Levy 2010; Young et al. 2005). Epicenters of disease are facilitated in prisons for several reasons: poor ventilation - under potentially unsanitary conditions, limited access to healthcare, overcrowding, and elevated health-related risk factors for inmates (Dolan et al. 2016). Moreover, incarceration often requires people to gather in close proximity, and may act as a source of infection, spreading infectious disease within and beyond prison walls. In the United States, by May 13, at least 25,239 inmates tested positive for COVID-19, with 373 related deaths. Also 6779 prison staff members tested positive, and 28 staff deaths were reported (Park and Meagher 2020). To combat the spread of infection in prison, the WHO provided global recommendations to combat the introduction, transmission and spread of the virus. Recommendations are similar to those for the general population, i.e., personal protection measures (hand washing, use of masks, etc.), environmental measures (disinfection procedures),

Maëlys Clinchamps

mclinchamps@chu-clermontferrand.fr

1 Université Clermont Auvergne, CNRS, LaPSCo, Physiological and Psychosocial Stress, University Hospital of Clermont-Ferrand,

Preventive and Occupational Medicine, Witty Fit, F-63000 Clermont-Ferrand, France

2 University Hospital of Clermont-Ferrand, Emergency Medicine, F-63000 Clermont-Ferrand, France

3 Preventive and Occupational Medicine, University Hospital of Clermont-Ferrand, F-63000 Clermont-Ferrand, France

4 Occupational and Environmental Medicine, University Hospital of Clermont-Ferrand (CHU), 58 rue Montalembert, 63000 Clermont-Ferrand, France physical distancing measures (especially for those with potential exposure), access restriction (suspension of visits) and movement limitations (WHO 2020). However, the reality is different with reports of inmates and staff not having personal protection equipment, and inmates living 2 or 3 to a cell, especially in a context of prison overcrowding. Beyond the vulnerability of prisons for outbreaks, the psychological vulnerability of inmates to the adverse consequences of preventive measures taken by prisons to contain the transmission of the virus must also be addressed. The measures put in place, notably the suspension of visits or activities during the pandemic, may induce major stress among inmates. A seminal study in mice showed that being able to stay active and to have control, even partial, are major factors in preserving health (Weiss 1970). Indeed, perceived inability to control a situation is characteristic of chronic stress and depression. The high prevalence of severe mental illness among inmates worldwide is well established, with one in seven inmates estimated to have major depression or psychosis (Yi et al. 2017). Despite recommendations, prisons are often neglected during catastrophes. The COVID-19 pandemic might exacerbate risk exposure in this underprivileged population. In addition to putative physical and psychological consequences in both inmates and staff within prisons, preventive strategies should be vigilant in avoiding potential clustering of COVID-19 cases, with putative spreading beyond prison walls and with consequences that outlast this virus.

Acknowledgements The editorial assistance of Pr. Geraldine Naughton is acknowledged in this letter.

\section{Compliance with ethical standards}

Conflict of interest The authors declare that they have no conflict of interest.

\section{References}

Dolan, K., Wirtz, A. L., Moazen, B., Ndeffo-Mbah, M., Galvani, A., Kinner, S. A., et al. (2016). Global burden of HIV, viral hepatitis, and tuberculosis in prisoners and detainees. Lancet, 388(10049), 1089-1102. https://doi.org/10.1016/s0140-6736(16)30466-4. 
McLeod, K. E., Butler, A., Young, J. T., Southalan, L., Borschmann, R., Sturup-Toft, S., et al. (2020). Global prison health care governance and health equity: a critical lack of evidence. American Journal of Public Health, 110(3), 303-308. https://doi.org/10.2105/ajph.2019. 305465.

Park, K., \& Meagher, T. (2020). A state-by-state look at coronavirus in prisons. The Marshall Project. Retrieved from https://www. themarshallproject.org/2020/05/01/a-state-by-state-look-atcoronavirus-in-prisons

Turner, K. B., \& Levy, M. H. (2010). Prison outbreak: pandemic (H1N1) 2009 in an Australian prison. Public Health, 124(2), 119-121. https://doi.org/10.1016/j.puhe.2009.12.005.

Weiss, J. M. (1970). Somatic effects of predictable and unpredictable shock. Psychosomatic Medicine, 32(4), 397-408. https://doi.org/ 10.1097/00006842-197007000-00008.
WHO. (2020). Preparedness, prevention and control of COVID-19 in prisons and other places of detention.

Yi, Y., Turney, K., \& Wildeman, C. (2017). Mental health among jail and prison inmates. American Journal of Men's Health, 11(4), 900-909. https://doi.org/10.1177/1557988316681339.

Young, L. C., Dwyer, D. E., Harris, M., Guse, Z., Noel, V., \& Levy, M. H. (2005). Summer outbreak of respiratory disease in an Australian prison due to an influenza A/Fujian/411/2002(H3N2)-like virus. Epidemiology and Infection, 133(1), 107-112. https://doi.org/10. 1017/s0950268804003243.

Publisher's note Springer Nature remains neutral with regard to jurisdictional claims in published maps and institutional affiliations. 